\title{
Texto historiográfico como "discurso de justificação": Cecília Westphalen e a construção de um lugar para si
}

\section{Daiane Vaiz Machado}

Universidade Estadual Paulista (Unesp/Assis)

\section{Resumo}

Fazemos, neste artigo, a leitura de textos de história da historiografia como "discurso de justificação". Os textos objetos foram produzidos entre 1983 e 1984 pela historiadora Cecília Westphalen (1927-2004) e promovem um balanço sobre a historiografia paranaense. Nestas produções, a autora buscou criar um sistema de referências para classificar os produtores de história e, assim, organizou uma linha evolutiva do modo como se fez história em diferentes temporalidades. Sua baliza decisiva foi a historiografia universitária da década de 1960 que, por sofisticar o campo historiográfico, corporificou o métier do historiador cientista. Seu exercício avaliativo retrospectivo também colocou em perspectiva as reminiscências de sua formação como historiadora e, então, apropriando-se deste gênero de escrita, Westphalen sugeriu o lugar que deveria ocupar na história da historiografia paranaense. É este processo de construção distintiva do historiador universitário, concomitante à construção da justificação de sua trajetória intelectual, que este artigo interpretará,

Palavras-chave: Discurso de justificação; Historiografia paranaense; Cecília Westphalén.
Historiographical text as "speech of justification": Cecília Westphalen and the development of a place for herself

\section{Abstract}

In this article we perused the texts about history of historiography as "speech of justification". The texts analyzed here were produced between 1983 and 1984 by the historian Cecília Westphalen (1927-2004) and promote a balance about Paraná state historiography. In these productions, the author pursued to create a reference system to classify the history productions and, thus, organized an evolutionary line about how the history was made in different periods. Westphalen's decisive guidance was the university historiography during the decade of 1960, which, by sophisticating the historiographical field, embodied the métier of the scientist historian. Her evaluative and retrospective exercise also put in perspective the reminiscences of her formation as a historian and, then, appropriating this genre of writing, Westphalen suggested the place she should occupy in the history of Paraná historiography. Is this process of distinctive construction of an university historian, concomitant to the construction of the justification of her intellectual trajectory, that this article will interpret.

Keywords: Speech of justification; Historiography of Paraná state; Cecília Westphalen. 

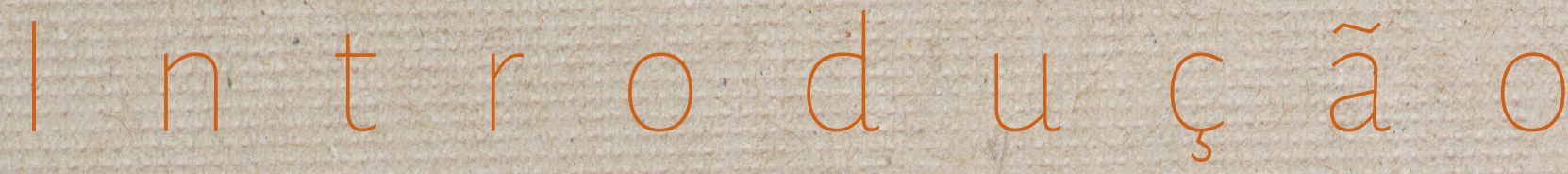

\section{N}

este artigo, lemos textos de história da historiografia como "discurso de justificação". Cecília Westphalen, historiadora da Universidade Federal do Paraná (UFPR), produziu fundamentalmente dois textos sobre historiografia paranaense. O primeiro foi escrito por ocasião da sua posse como sócia do Instituto Histórico e Geográfico Brasileiro (ICHB), em 1983, e o segundo (retomada sintética do primeiro) foi apresentado na reunião da Sociedade Brasileira de Pesquisa Histórica (SBPH), que, em 1984, devido à presença do historiador francês Charles-Oliver Carbonell, presidente da Comissão Internacional de História da Historiografia ${ }^{1}$, propôs como temática central a reflexão sobre essa emergente área de

1 A Comissão Internacional de História da Historiografia ou Comissão de História da Historiografia (visto que se encontram as duas denominações) teve origem em Bucareste, no interior do encontro do Comitê Internacional de Ciências Históricas (CISH), em 1980. Na ocasião e por aquele grupo de participantes, a história da historiografia teria sido reconhecida como disciplina. A partir de então, sob a liderança de Carbonell, fundou-se um grupo que tinha coma, objetivo legitimar e divulgar as potencialidades investigativas desta nova área e galgar espaço institucional (CUIMARÃES, 2011, p. 21). estudos. Nestas duas produções, Westphalen criou um sistema de referências para classificar os produtores de história e, assim, organizou uma linha evolutiva do modo como se fez história em diferentes temporalidades. Sua baliza decisiva foi o encontro da historiografia universitária brasileira com a historiografia francesa dos Annales, na década de 1960, que por sofisticar o campo historiográfico, teria corporificado o métier do historiador cientista.

Na ocasião da primeira apresentação do texto sobre historiografia paranaense, Westphalen estava com 56 anos, sendo 32 deles dedicados ao ensino e à pesquisa histórica. Uma avaliação do percurso da história no Paraná significava também inserir no discurso as reminiscências de sua formação historiográfica. A autora, quando se voltou ao seu próprio passado, também colocou a nu como se fez historiadora e, assim, como exploraremos, sugeriu - lugar que deveria ocupar na história da historiografia paranaense. 


\section{Historiografia paranaense e o seu não dito}

Cecília Westphalen não escreveu uma obra dedicada exclusivamente à história da historiografia, seja brasileira ou paranaense- - este não foi seu campo de estudo privilegiado. Produziu, no entanto, além dos dois artigos sobre historiografia paranaense mencionados (WESTPHALEN, 1984; 1985a), análises historiográficas a respeito de Fernand Braudel (WESTPHALEN, 1982; 1983a; 1985b) e Gilberto Freyre (WESTPHALEN, 2000) ${ }^{2}$. Como pesquisadora, sua esfera de atuação foi predominantemente econômica e social (com incursões pela demografia histórica) e o seu marco espacial de investigação foi o Paraná. Contudo, a alta circulação em diferentes sociedades de produção do conhecimento histórico, no Brasil $^{3}$ e no exterior ${ }^{4}$, co-

2 A Palavra do Sul. Cem anos de Gilberto Freyre (2000) é uma coletânea de artigos escritos por Westphalen desde a década de 1980. O livro é a expressão da transmutação dos laços profissionais em laços afetivos a partir do trabalho conjunto de Westphalen com Freyre no Conselho Federal da Cultura, entre 1976 e 1983.

3 Entre elas está a Associação Nacional de História (ANPUH) e a Sociedade Brasileira de Pesquisa Histórica (SBPH). O rompimento de Westphalen com a ANPUH, no Simpósio Nacional de 1977, foi um dos propulsores à criação SBPH, que foi idealizada com as colegas Maria Beatriz Nizza da Silva (USP) e Altiva Pilatti Balhana (UFPR). A sociedade permaneceu ativa no meio intelectual brasileiro de 1981 a meados de 2005.

4 Entre as quais destacamos: Comission Internationale d'Histoire des Mouviments Sociaux et des Structures Sociales, do CISH ligado à UNESCO; Asociación de Historiadores Latinoamericanos y del Caribe (ADHILAC Internacional); e Société de Démographie Historique. locava Westphalen em contato com uma série de temas, abordagens, estilos, problemáticas, rivalidades e impasses, como a da historiografia da Nova História, narrada por, Carbonell na conferência proferida na $\mathrm{SBPH}^{5}-$ que colocou em questão as escolhas que ela fizera outrora, ou sejà, seu direcionamento historiográfico à história econômica, praticada com métodos estatísticos e quantitativos, à la Annales. Voltando-nos às circunstâncias de produção dos dois textos aqui analisados, diríamos que, foi percebendo que a historiografia estava em pauta $^{6}$, que Westphalen sistematizou uma reflexão sobre a história da historiografia paranaense e serviu-se deste gênero de escrita para, por vias indiretas, compor um documento sobre si, emoldurar uma imagem.

Na esteira de Cérard Noiriel (2014), analisaremos os ártigos de Westphalen como "discurso de justificação". Para este analista das práticas dos historiadores franceses do século $X X^{7}$, uma boa parte

50 título da conferência de Carbonell na SBPH foi Questions à la "Nouvelle Histoire". Organizaram-se duas mesas-redondas: uma foi comandada por Nizza da Silva, professora titular de Teoria e Metodologia da História da Universidade de São Paulo (USP), que debateu sobre "História Comparada da Historiografia"; e a outra mediada por Cecília Westphalen, professora de História Moderna e Contemporânea da UFPR, com o tema "Historiografias regionais".

6 Segundo François Hartog (2011, p. 248) e Rodrigues e Nicolazi (2012, p. 356-357), seria possível perceber, nas décadas de 1970 e 1980, um "movimento historiográfico". 7 A obra de referência do autor é Sur la "crise" de l'histoire, de 1996 (NOIRIEL, [1996] 2005). 
dos escritos sobre a história destina-se a "defender seus propósitos anteriores, sua posição acadêmica, suas ambições ou sua notoriedade" (NOIRIEL, 2014, p. 37) ${ }^{8}$. As práticas de justificação, acrescenta Noiriel, fazem parte dos constrangimentos que pesam sobre a diversidade das atividades profissionais que compõem o métier do historiador? e, por isso, são recorrentes em momentos de defesa de especificidades, de tomadas de posição e de inauguração de perspectivas, que implicam, até mesmo, a desqualificação dos predecessores. Caso representativo, para ele, é o do "chefe de obra" Fernand Braudel (2009) nos Escritos sobre a História ${ }^{10}$. Neste exercício interpretativo, não se trata de

8 "défendre leurs propos antérieurs, leur positions académique, leurs ambitions ou leur notoriété" (NOIRIEL, 2014, p. 37).

9 Referimo-nos à moderna estrutura universitária, na qual o docente tem múltiplas incumbências: ensinar, produzire divulgar o conhecimento, gerir orientandos, julgar seus pares, tomar assento na burocracia institucional.

10 Noiriel (2014) coloca em perspectiva a historicidade dos Escritos sobre a história, coletânea de artigos redigidos de 1940 a 1960, na trajetória intelectual de Braudel. Sua interpretação questiona como o autor de OMediterrâneo reescreveu seu prefácio original para inscrever sua concepção do tempo em história na história da disciplina. Essa reescrita tem como epicentro os debates travados com o etnólogo Claude Levy-Strauss quanto à sua definição dos papéis que a Etnologia e a História desempenhavam na produção do conhecimento. Em resposta ao desafio anti-histórico da Antropologia estruturalista, Braudel elaborou um plano de ação onde a História e a noção de longa duração estavam no centro. A História, regente da orquestra, com o conceito de multiplicidade do tempo social, linha capaz de condicionar até as estruturas mais imutáveis, jntegrava as ciências sociais, cujo objeto comum é o homem em sociedade (BRAUDEL, 2009; DOSSE, 1992). propor que todos os textos que constroem balanços de história da historiografia possam ser lidos desta forma, mas, de mostrar como este caminho pode ser pertinente para problematizar a personalização "não dita" deste tipo de escrita.

Trabalharemos, então, com os dois exemplares publicados por Westphalen $(1984 ; 1.985 a)$, e com anotações esparsas e esboços que os originaram, nos quais é possível encontrar formulações, sentenças e desacordos que não aparecem no texto final ${ }^{11}$. Certamente, são múltiplas as razões que convergem para as supressões textuais - seja a revisão da ideia, considerada inadequada, seja o próprio cerceamento, prevendo as críticas geradas pela escrita (que talvez não possam ser contra argumentadas) e desagrados (de ordem científica, hierárquica, política). Sem pretender determiná-las, acreditamos que perseguí-las abre brechas para problematizar o "não dito" da construção publicável. Quando Michel de Certeau (2002) se referiu ao "não dito" da operação historiográfica, remeteu-nos ao lugar do sujeito construtor da interpretação

11 Estes vestígios de sua prática historiadora compõem a Coleção Cecília Westphalen, formada por seu arquivo pessoal, depositado no Arquivo Público do Paraná. 
histórica. Como ser mutável, participante de conflitos sociais e epistemológicos, seu produto historiográfico, apesar da imposição de um "sistema de referências", é dotado de subjetividade, de presença do presente, de predileções (filosofias individuais) que, para Certeau, como componentes da operação historiográfica, deveriam ser elucidados ao leitor (CERTEAU, 2002, p. $67-69 ; 2016$, p. 50-51). No encalço desta compreensão certeauniana, também indagamos as escolhas textuais de Westphalen pela lente das tensões intelectuais do presente que estruturou sua escrita.

Para iniciarmos, trabalhemos com o explícito, com o sistema de referências que a historiadora estabeleceu para organizar sua exposição sobre a escrita da história no Paraná:

Alicerçada na produção de Eduard Fueter $^{12}$, Westphalen (1984, p. 109) compreendia que a tarefa da historiografia consistia em "retraçar e explicar o movimento cumulativo" da História.

12 Fueter, historiador suíço, escreveu Geschichte der neuren Historiographie, publicada em 1911. Na obra de Fueter, segundo Valdei Araújo, "encontramos uma narrativa triunfal da emergência dos padrões modernos da disciplina histórica. [...] tratava-se de um relato teleológico que avaliava as historiografias do passado a partir desse projeto de cientifização" (SILVA, ALVES \& ASSUNÇÃO, 2014, p. 310).
A direção deste retorno à produção do passado era sinalizada pela história como ciência, ou seja, a obra era avaliada a partir de princípios próprios do lugar de onde Westphalen falava: a história universitária. Então, tratava-se de narrar o processo de gestação da "ciência histórica" no Paraná, "feito de aquisições, de correções, de aprofundamentos, de progressos" (WESTPHALEN, 1984, p. 109). Esta definição partia de sua leitura da tradução de Ceschichte der neuren Historiographie, que Fueter $(1953$, p. 7) concebeú em 1911 para "traçar a história da historiografia européia do humanismo aos nossos dias", considerando "a história das teorias históricas e do método histórico na medida em que elas parecem ter influenciado no desenvolvimento da historiografia" (FUETER, 1953, p. 7$)^{13}$.

Os críticos de Fueter costumam classificar sua volumosa obra como "bibliográfica", "erudita" e "enciclopédica", em que "nomes dos historiadores e ós títulos das obras se sucederam rápida e abundantemente, precedidos

13 "trazar la historia de la historiografía europea desde el humanismo hasta nuestros días", considerando "la historia de las teorias históricas y del método histórico sino en tanto que ellas parecen haber influído en el desenvolvimiento de la historiografía" (FUETER, 1953, p. 7). 
por quadros de interpretação geral minimamente esboçados" (MASTROGRECORI, 2009, p. 66). Ao afastar a história da teoria da história, ele teria qualificado a historiografia como "pesquisa histórica exclusivamente", ponderando-a a partir de um ideal de historiografia moderna (BLANKE, 2009, p. 28). Seu empreendimento geralmente é lembrado para marcar um estilo característico do nascimento de obras dedicadas à história da historiografia.

Situar a crítica dirigida a Fueter não implica enquadrar Cecília Westphalen nela, como se ela fosse uma fiel discípula. A produção desse historiador foi seu ponto de partida, é a única referência da área citada em seus textos. Com ela, Westphalen conheceu os "princípios de classificação" traçados por Fueter e, adaptando-os aos seus interesses históricos particulares, os ampliou.

Segundo Westphalen (1984, p. 109), a pesquisa em historiografia deveria iniciar-se pela sistematização dos "critérios de seletividade", os quais garantiriam que o trabalho não caísse na armadilha da produção de um "elenco bibliográfico", de um "dicionário de nomes de historiadores" - ironicamente, justamente a crítica tecida à Fueter. Preocupada em estabelecer bases seguras para apoiar-se - seguindo as regras de um trabalho cientificamente orientado -, Westphalen (1984, p. 109) forjou um método de classificação, que abrangia

os iniciadores, os originais, os que conservam o seu valor, os que apontam direções principais, os que constituem escola. São critérios includentes, mas existem ainda os excludentes, sobretudo, daqueles que são meros repetidores do que outros já escreveram, os eternos parafraseadores. Assim, também, aqueles que, em suas obras, gerais ou mesmo específicas, apenas tangenciavam a história do Paraná. E, por último, o mais grave, os levianos, de afirmações gratuitas, infundadas ou mesmo'inverídicas.

Este método a guiaria no ordenamento da narrativa de como a.história foi praticad’a no Paraná. Conjugada à preocupação da instituição do método, estava a "problemática da datação". A consideração do tempo, matéria fundamental do historiador - "como a terra que adere à pá do jardineiro", diria Westphalen (1984, p. 109), evocando a célebre frase de Braudel-, trazia especificidades à historiografia, pois "pe- 
riodizar em historiografia é tanto mais complicado que na História, onde as estruturas, as conjunturas e os fatos são datados e situados, no tempo e no espaço. Na historiografia, há a interseção do tempo da História e do tempo do historiador" (WESTPHALEN, 1984, p. 109).

Essa formulação deixa margem à dubiedade, mas investiremos na ideia de que ela se referia ao tempo do historiador analisado, o que implicaria o inter-relacionamento entre as condições socioeconômicas, políticas e o desenvolvimento da escrita. O texto só poderia ser compreendido se merguIhado em sua historicidade, numa linguagem mais westphaleniana, no "estado de civilização" em que emergiu. A transformação deste estado era estabelecida pela "avaliação do significado da mudança". No caso do Paraná, ela identificou três momentos de longa duração, ou seja, três momentos que teriam marcado a estrutura da escrita da história no espaço paranaense.

\section{O primeiro momento é representado} pelo retrato que viajantes e cronistas traçaram de uma comunidade embrionária, o Paraná do século XIX.
Como memórias e relatos de viagem, esse material foi analisado em função do seu potencial documental. Westphalen partilha do ponto de vista de seu contemporâneo e amigo Francisco Iglésias $(2000)^{14}$, ao considerar a produção de viajantes e cronistas fundamental para a historicização da formação histórica de uma sociedade e para balizar a mudança. Auguste de Saint-Hilaire, Avé-Lallement, Thomas P. Bigg Wither (como viajantes), Salvador Correia Coelho e Antonio Vieira dos Santos (como cronistas), são os autores elencados.

Com Saint-Hilaire, Westphalen colocou em exercício os princípios da crítica metódica, seu intuito foi demonstrar que a negligência de sua aplicação poderia causar sérias consequências à

14 No acervo pessoal de Westphalen no Arquivo Público do Paraná, encontramos 11 cartas recebidas de Iglésias. 0 principal tema da correspondência entre eles eram os relatórios para o'CNPq. Westphalen, que também foi assessora do órgão de fomento, foi leitora de alguns dos textos avaliativos de Iglésias sobre a área de História. Os pedidos de indicações, "sugestões para cortes e acréscimos", eram recorrentes da parte de Iglésias. Da parte dele, também, eram constantes os elogios na apreciação das obras que Westphalen Ihe enviava de presente: "Costei muito de seu estudo sobre a historiografia paranaense, o que mais me valeu para o meu propósito neste momento. Muito obrigada por tudo, cara Cecília" (ICLÉSIAS, 1986); "Quero agradecer-lhe o generoso envio de seu último trabalho - O BARÃO DOS CAMPOS CERAIS E O COMÉRCIO DAS TROPAS. Fico feliz em ver que continua operosa, entregue às pesquisas e sabendo colocar os resultados em livros ricos de informação e interpretações sempre lúcidas. Salve, Cecília, a intelectual consciente, a historiadora exemplar" (ICLÉSIAS, 1995). 
formulação de uma imagem do passado. Segundo Westphalen (1984, p. 113), era

preciso ler e reler Saint-Hilaire, como qualquer dos outros deslumbrados viajantes europeus, ou seja, com muito cuidado. Se, nas descrições das paisagens e dos eventos, elas parecem precisas do ponto de vista qualitativo, de outro lado, é necessário criticar, atentamente, os dados quantitativos apresentados, frutos quase sempre da informação oral presente ou fornecida posteriormente.

Colando o escrito nas condições econômicas e sociais de sua produção, Westphalen (1984, p, 113) confrontou a narrativa do viajante com dados extraídos de censos e listas nominativas de habitantes, e assim desmistificou dois enunciados: "o da remota branquidade dos paranaenses e o da inexistência de escravos no Paraná". Seu alvo foi a tese do "Brasil diferente", formulada por Wilson Martins (1955) e assentada na defesa da insignificância do contingente negro no Paraná ${ }^{15}$. Deste modo, pela abordagem historiográfica, Westphalen promoveu a desconstrução de um mito identitário, demonstrando a potencialidade críti-

15 A tese do "Brasil diferente" também pode ser lida em Linhares (1953). Para a crítica contemporânea desta tese, ver Moraes; Souza (1999) e Oganauskas (2013). ca desta forma de narrativa retrospectiva sobre a prática da história.

As narrativas de Saint-Hilaire e dos demais viajantes eram deliciosas descrições do cotidiano, mas eram parciais, limitadas pelo testemunho oral e pela visão escancarada; logo, carregadas de subjetividade. Subjetividade intrínseca a um texto escrito fora de uma regulação científica e, portanto, reveladora da visão turva advinda de um conhecimento não científico.

Prenuncia o fim desse primeiro momento o aparecimento do "pai da história". Antônio Vieira dos Santos, leitor da filos.ofia da história de Cícero e conhecedor de práticas heurísticas, "sem cuja referência não existe a historiografia paranaense", tinha postura de historiador: "Ele vai aos arquivos, consulta as fontes, tanto as antigas, como modernas, extrai os acontecimentos originais, e adota um método para ordená-los, o cronológico". (WESTPHALEN, 1984, p. 117).

Diferente de Saint-Hilaire, Vieira dos Santos fundamentava sua escrita em fontes, tinha a inquietude de checar as informações, o que, aos olhos de Westphalen, tornava seu texto confi- 
ável ao investigador contemporâneo. A historiadora também não deixou de assinalar sua percepção avançada para época, uma vez que ele se serviu de documentos considerados fundamentais para os estudos contemporâneos de história econômica e demográfica, os "mapas demonstrativos de estatísticas populacionais, do movimento do porto, com suas importações e exportações, rendas fiscais, entradas e saídas de embarcações", rompendo, assim, o quadro estrito da narração dos eventos notáveis da história (WESTPHALEN, 1984, p. 117).

A obra de Vieira dos Santos ${ }^{16}$ é tomada como marco final do primeiro período. Esta foi escrita na conjuntura do aguçamento dos jogos políticos para a emancipação do Paraná, que até 1853 era a $5^{a}$ Comarca da Província de São Paulo $^{17}$, e do gérmen do sentimento

16 Segundo Paulo Benatte (2012), em que pese o gosto pelo arquivo e a concepção de prova de Vieira dos Santos, "de modo geral, a escrita da história em Vieira dos Santos está mais próxima da narrativa literária que dos modelos, emergentes na Europa, da história ciência". A esse respeito, ver também Comes (2012).

17 Para Divonzir Lopes Beloto (2003), a elite campeira e os ervateiros não conseguiram se articular enquanto "grupo" com força política organizada o suficiente para ser ouvida pelo Império. Defende Beloto que a emancipação foi fruto de uma manobra política do Partido Conservador para desarticular o crescimento do Partido Liberal na Comarca de Curitiba, garantindo, desta forma, a vitória dos conservadores em São Paulo nas eleições de 1854. "paranista" de valoração regional. o cume deste discurso se situa na virada para o século XX e está entrelaçado aos conflitos político-militares da Revolução Federalista e do Contestado. No segundo momento, observamos um fenômeno de geração. Rocha Pombo, Romário Martins, Ermelino de Leão, Moysés Marcondes, Francisco Negrão "e tantos outros nomes ilustres" são da "geração que, em 1900, funda o Instituto Histórico e Ceográfico do Paraná" (WESTPHALEN, 1984, p. 110). Estes autores, a "ínclita geração", tornaram-se referência naquele período pela tentativa de corporificar, por meio da escrita da história, a História do Paraná.

Rocha Pombo foi o primeiro "historiador da sociedade paranaense", pois segundo Cecília Westphalen (1984, p. 118), em Paraná no Centenário (1900), "o povo está presente". Tal "como Henri Berr e a Synthèse Historique", o historiador foi "além da simples ordenação causal dos fatos e da consideração apenas dos grandes homens". Ele soube ler o seu presente.

Romário Martins teria tido esse mesmo espírito na condução de sua obra. Apesar de não ter se referido aos seus 
"critérios historiográficos [...], tão pouco ao método adotado, nem mesmo às suas finalidades" (WESTPHALEN, 1984, p. 118-179), foi o fundador de uma história regional "como estudo de uma comunidade orgânica que se desenvolve através do tempo em organizações sociais que se integram com as conjunturas da história nacional global", como avaliou Brasil Pinheiro Machado (1974, p. 58, apud WESTPHALEN, 1984, p. 119), leitor especializado nos critérios que Martins teria negligenciado ${ }^{18}$. Outra ledora de Martins, digna de nota por Westphalen, foi sua colega de ofício Altiva Pilatti Balhana, que reconheceu na obra do paranaense o interesse pelo número e pela estatística populacional ${ }^{19}$.

Os demais autores analisados foram Ermelino Agostinho de Leão e seu Diccionário Histórico e Ceográfico do Paraná (1926), e Francisco Negrão, autor do Boletim do Archivo Municipal de Curitiba (1906-1932) e da Cenealogia Para-

18 Brasil Pinheiro Machado (19.07-1997) ocupava a função de catedrático em História do Brasil na UFPR, instituição onde foi também Vice-Reitor. Sobre sua trajetória intelectual, ver Marchette (2013).

19. Altiva Pilatti Balhana (1928-2009), companheira de Westphalen, era professora de História da América na UFPR, pesquisadora da imigração italiana no Paraná e referência em História Demográfica. Cf. Balhana (1958; 1978), Henrye Balhana (1975), Balhana e Westphalen (2003). naense (1926-19.50). Tais obras foram inseridas neste panteão pelo grande trabalho heurístico, cuja composição estava fadada a ser "de grande interesse para os modernos demógrafos e historiadores sociais" (WESTPHALEN, 1984, p. 120) ${ }^{20}$.

A Sinopse da História do Paraná, de Brasil Pinheiro Machado, apresentada ao Instituto Histórico, Ceográfico e Etnográfico do Paraná em 19.51, espécie de projeto de como deveria ser escrita a História do Paraná, assinala o terceiro momento. Mais uma vez, um evento político baliza sua periodização: as preparações para o Centenário de Emancipação do Paraná, que ocorreria em 1953. Esse projeto foi o primeiro produto do curso de História e Ceografia da Fáculdade de Filosofia, Ciência e Letras do Paraná, criado em 1938. O marco deste terceiro momento estaria entre 1938 e 1951: não poderia ser 1938 pela coexistência de "formas tradicionais e modernas" (o moderno estaria representado pelo convívio da História com outras Ciências Sociais), a qual findaria em 1957, período de

20 Para não passar em branco, Westphalen (1984, p. 121) julgou pertinente citar, ainda, dois estrangeiros: Fugmann e Brepohl; além do cientista social Octávio lanni, e sua obra As metamorfoses do escravo, de 1962. 
apelos desenvolvimentistas no Brasil. Assim, o terceiro momento alcançaria seu auge a partir de 1959, quando

De regresso da França, em 1959, onde estudara com Fernand Braudel, Jean Meuvret e outros, eu própria traria para difusão entre os meus colegas e discípulos, o conhecimento da escola de Annales, com os conceitos fundamentais da multiplicação do tempo histórico e o emprego da quantificação na História (WESTPHALEN, 1984, p. 171).

O uso da primeira pessoa nesse trecho mira os holofotes, na sua experiência pessoal. O seu retorno da $V I^{a}$ Section de l'École Pratique des Hautes Études (EPHE) representa a inserção da historiografia paranaense no que de mais atual havia no campo internacional da História. Com Brasil Pinheiro Machado, Altiva Pilatti Balhana e ela mesma, o Departamento de História da UFPR tornava-se um lócus de investigação social e econômica, com foco nos estudos de imigração, nas relações comerciais e nas estruturas agrárias. A exploração de novas fontes pelo projeto de levantamento de arquivos, e o "emprego da quantificação na História", teriam permitido um "alargamento dos campos de pesquisa e mesmo a renovação da historiografia parànaense, agora em bases rigorosamente científicas" (WESTPHALEN, 1985a, p. 60).

Segundo Westphalen, graças a estas diretrizes, na alvorada da década de 1970 a UFPR esteve entre as primeiras instituições que implantaram os cursos de Pós-Graduação em História, que pela "qualidade e rigor teórico, temático e metodológico" representavam um nível de sofisticação do conhecimento histórico jamais visto na historiografia paranaense. Os frutos que adviriam dos trabalhos de Sergio Odilon Nadalin, Jayme Antonio Cardoso e Márcia de Campos Graf certamente encaminhariam a historiografia paranaense para o seu quarto momento (WESTPHALEN, 1985a, p. 60).

Westphalen reforça que a metodologia privilegiada foi o recorte regional. Este acento tem um caráter político-ético: o’produto do interesse histórico pelo conhecimento do espaço regional era arma para refutar o argumento de que "o Paraná, terra nova; explodindo com a cultura cafeeira, não teria história" (WESTPHALEN, 1985a, p. 61). A explicação estaria na marginalização das historiografias regionais fora do eixo Rio-São Paulo. Assim como 
era tarefa do historiador desconstruir mitos identitários, ele também deveria contra- atacar verdades invisivelmente instituídas.

Nos textos sobre historiografia paranaense, Cecília Westphalen traçou os temas, as aproximações teóricas e os métodos utilizados pelos autores elencados. Com seus critérios de classificação, formulou quadros interpretativos para essa historiografia, interligando-a à conjuntura política e social (mais política que social). Apesar de demarcar a historiografia entre tradicional e moderna, ela buscou não hierarquizá-la explicitamente, pautando-se no argumento de que a história de seu tempo era vista de outro ponto, pois

se a historiografia tradicional foi, sobretudo, política, diplomática, militar, a pressão dos fenômenos econômicos e sociais, até mesmo a pressão demográfica dos niossos dias, colocam em evidência novas problemáticas (WESTPHALEN, 1984, p. 125).

Fica claro que Westphalen, compreendia a historiografia como partícipe do processo histórico-social, por isso a escrita da história tem uma história.

Se de um lado Westphalen faz da história da historiografia um meio para evidenciar a variedade das maneiras de se relacionar com o passado, de produzir história, de outro ela assenta a boa condução da história no Paraná, instrumentalizando a abordagem para erigir uma memória disciplinar ${ }^{21}$.

Chegando ao término de sua exposição, é producente confrontá-la com o comentário que Westphalen destilou ao Roteiro sucinto do desenvolvimento da historiografia brasileira, de Alice Piffer Canabrava (USP), no "Encontro Nacio-

21 Como refletiu Manoel Luiz Salgado Cuimarães (2005, p. 32), "Nossa própria disciplina tem a sua história, fruto de embates e tensões, disputas por memória, uma memória disciplinar que uma vez instituída tende a canonizar autores e obras constituindo o panteon dos nossos clássicos". $\mathrm{Na}$ trilha da problemática levantada por Guimarães, Rodrigo Turin (2013, p. 78-95) coloca em discussão "os usos e sentidos que configuram a história da historiografia como gênero de escrita da história". Buscando na historicidade da historiografia os enunciados que conformaram a sua forma, 0 autor apontou, em um desses momentos, como a delimitação do gênero e sua institucionalização se processaram de forma simultânea à disciplinarizaçã̃o do saber histórico. 
nal de Estudos Brasileiros, I Seminário de Estudos Brasileiros", promovido pelo Instituto de Estudos Brasileiros em 1971. Nesta década, Westphialen (1972, p. 39) afirmou que a historiografia brasileira pós-Capistrano de Abreu até meados da década de 1960 era caracterizada pelo "marasmo, [pel] a ausência de pesquisa e uma produção fragmentária". Aproximando as avaliações de Westphalen em 1971 e 1983/1984, percebemos que há um recuo nesse julgamento. Como compreender tal reconsideração para o caso da historiografia paranaense?

Um dos elementos que colocamos em discussão é a instituição da própria genealogia de Westphalen como historiadora. O fato de conferir destaque apenas a obra de Brasil Pinheiro Machado evidencia, de sua parte, que não haveria outros historiadores para serem lembrados a partir da fundação do Curso de História e Geografia, mas isto não precisaria aparecer no texto, já que denunciaria os problemas de sua formação, os quais ela talvez não tivesse interesse em discutir naquela ocasião. Melhor seria inscrever no passado, mais evidentemente no segundo momento, grossos e recorrentes grifos em indícios de aproximações com as ciências sociais, com o tratamento de dados numéricos, estatísticos e censitários na abordagem do econômico e social. Assim, o conhecimento que se fez, desde 1959, da história econômica e social praticada pelos Annales, foi conjugado a esta tradição, espécie de proto-história econômica e demográfica com prática quantitativa. A construção de sua genealogia historiográfica também é capaz de explicar a escolha de Fueter como referência aos estudos de história da historiografia, ao invés de apoiar-se em uma bibliografia mais atualizada, como a desenvolvida no campo historiográfico francês. Esta bibliografia francesa se constituiu colocando em perspectiva crítica o fazer história dos Annales, ou seja, questionando os postulados pelos quais Westphalen se formou como pesquisadora e formou uma legião de historiadores na UFPR.

Incursionando pelo "não dito", observamos que, nos textos publicados, Westphalen (1983b, p. 23) suprimiu este final: " $E$, como ensinava Lucien Febvre, História é filha do seu tempo. Aí estão as 50 Dissertações e 13 teses filhas destes 25 anos". O cálculo dos 25 anos não coincide com o ano de instituição do Curso de História e Ceografia em 1938. 
mas sim com a partida da historiadora para seus cursos de especialização na Alemanha e França, em 1958. como marco de referência. Nome que ficaria associado à instituição de um projeto para estudar o comércio exterior do Paraná através do Porto de Paranaguá, "realizando o que Chaunu denominou de história serial, inclusive com o emprego de processamento eletrônicos dos dados e de técnicas da semiologia gráfica" (WESTPHAria" (CONTI)O, 2011, p.

científica. Justificam-se as

suas escolhas e planta-se a boa repercussão da sua trajetória historiográfica.
279). Com a narrativa de Westphalen, a cientificidade da historiografia paranaense ganhava um lugar - o curso de História, já em processo de separação do Curso de Ceografia -, e um agente - Cecília Westphalen, a partir de sua experiência europeia entre 1958 e 1959. Estabelece-se, então, um pacto de correspondência, de entrelaçamento da sua trajetória pessoal ao curso de História, em sua guinada científica. Justificam-se as suas escoIhas e planta-se a boa repercussão da sua trajetória historiográfica.

Westphalen forja a tradição da produção científica da história no Paraná e, de' forma sutil, oferece seu nome
LEN, 1984, p. 123) ${ }^{22}$. Porém, esta não foi sua primeira produção no campo da história. Em 1953; ano de comemoração dos cem anos de emancipação política do Paraná, Westphalen estreou no mercado editorial com o livro Pequena História do Paraná e, em 1958. publicou Carlos-Quinto, 1500/1558: seu Império universal, tese apresentada para a cátedra de História Moderna Contemporânea da UFPR, em 1955. Grosso modo, as duas obras simbolizariam uma escrita de valorização do factual, construída majoritariamente com material bibliográfico e com foco em uma história política habita-

220 resultado final deste projeto é a obra Porto de Paranaguá, um sedutor, publicada em 1998. 
da pela ação de grandes lideranças, ou seja, naquele instante da escrita, elas representavam uma herança historiográfica pela qual Westphalen' não trabalhava para ser lembrada. Logo, poder-se-ia dizer, há nos textos sobre historiografia paranaense uma velada tentativa de desvinculação, de descolagem, destas suas primeiras incursões ao passado.

Na trajetória intelectual de Westphalen, o momento da escrita dos textos sobre historiografia paranaense é assinalado por reveses na sua posição no campo historiográfico, Por confrontos de poder com seus ex-discípulos, ela sofria o enfraquecimento interno de sua figura no Departamento de História da UFPR; também, progressivamente, afastava-se de postos administrativos de comando; por divergências ideológicas e epistemológicas, havia rompido com a ANPUH, até então seu principal espaço nacional de sociabilização do conhecimento histórico. Contrária à dita politização e polarização do discurso de esquerda, reinante na associação no fim dos anos 1970, a historiadora colocava-se como partidária da neutralidade científica. Suas boas relações com a cúpula governamental, que até então auxiliavam no funcionamento administrativo da associação ${ }^{23}$, passaram a ser simétricas a uma postura colaboracionista do regime militar como um todo ${ }^{24}$.

Quanto à produção historiográfica, Westphalen, atenta ao estado da pesquisa no campo, compreendia muito bem o progressivo desinteresse pela história que praticava: a história econômica com fontes seriais e técnicas estatísticas ${ }^{25}$. Os escritos sobre a historiografia paranaense rememorariam a importância que conheceu esta abordagem para a sofisticação da pesquisa histórica e divulgariam, via quarto momento, a expectativa de longevidade acenada pela geração de mestres e doutores (WESTPHALEN, [198-], p. 2).

Compreende-se, assim, o quanto as preocupações e escolhas textuais de Cecília Westphalen estavam relacionadas àś experiências sentidas, isto é, à sua trajetória intelectual.

23 Westphalen exerceu a função de Tesoureira da ANPUH até 1977.

24 Esta mácula que recaiu sobre Westphalen foi externada em uma de suas mais longas entrevistas: "Há", disse ela em 1988, "uma mancha na minha testa: 'colaborou com a ditadura, colaboracionista'. [...] Há muitos professores marginalizados porque ocuparam cargos no período" (PROJETO MEMÓRIA VIVA PARANÁ, 1988):

25 Sobre o estado da questão em história econômica, ver Westphalen (1986), Fragoso e Florentino (1997), e Motta (2009). 


\section{Considerações finais}

No jogo entre dito e não dito, anàlisado por meio das escolhas textuais e do lugar social de Cecília Westphalen, propusemos ler sua produção sobre o percurso da história no Paraná como um "discurso de justificação". Notamos, assim, que Westphalen buscou construir uma identidade historiográfica a partir de sua auto localização no momento de guinada científica da historiografia paranaense. Embora ela não tenha escrito um relato biográfico, nos moldes do que, se identifica como "escrita de si" (ARFU$\mathrm{CH}, 2010$; LELEUNE, 2008), nas narrativas analisadas (exercícios de construção objetivante de uma prática em um espaço regional, a escrita da história no Paraná), a autora ofereceu os contornos para o enquadramento da sua lembrança: Cecília Westphalen indicou as linhas que comporiam seu obituário.

\section{Referências}

\section{Fontes primárias:}

IGLÉSIAS, Francisco. [Carta] 28 out. 1986, Belo Horizonte [para] WESTPHALEN, Cecília, Curitiba. Agradece recebimento de publicações. Coleção Cecília Westphalen. Arquivo Público do Paraná, Caixa 10.

[Carta] 1 set. 1995, Belo Horizonte [para] WESTPHALEN, Cecília, Curitiba. Agradece recebimento de publicações. Coleção Cecília Westphalen. Arquivo Público do Paraná, Caixa 9. PROJETO MEMÓRIA VIVA PARANÁ. Entrevista com a Professora Cecília Westphalen. Curitiba: Umuarama Comunicação e Arte, 1988. 1 DVD.

WESTPHALEN, Cecília M. Proposta de periodização: o que constituia História do Paraná? [198-], p. 2. Coleção Cecília Westphalen. Arquivo Público do Paraná, Caixa 20.

[Historiografia paranaense]. 1983b, p. 23. Coleção Cecília Westphalen. Arquivo Público do Paraná, Caixa 17.

\section{Fontes bibliográficas:}

ARFUCH, Leonor. O espaço biográfico: dilemas da subjetividade contemporânea. Rio de Janeiro: UER], 2010. 
BALHANA, Altiva.P. Santa Felicidade: um processo de assimilação. Curitiba: ]. Haupt, 1958.

Santa Felicidade: uma paróquia Vêneta no Brasil. Curitiba: Fundação Cultural, 1978

BALHANA, Altiva P.; WESTPHALEN, Cecília M. Um Mazzolino de Fiori. Curitiba: Imprensa Oficial; Secretaria de Estado da Ciência, Tecnologia e Ensino Superior, 2003. 3 v.

BELOTO, Divonzir Lopes. A criação da Província do Paraná: a emancipação conservadora. 2003 Dissertação (Mestrado em Economia) - Pontifícia Universidade Católica de São Paulo, São Paulo. 2003.

BENATTE, Antonio P. A escrita da história em Antônio Vieira dos Santos (1850/51). In: ENCONTRO ESTADUAL DE HISTÓRIA ANPUH-PR, 13, 2012, Londrina. Anais... Londrina: UEL, 2012, p. 799-810.2V.

BLANKE, Horst W. Para uma nova história da historiografia. In: MALERBA, 7. (Org.): A história escrita: teoria e história da historiografia. São Paulo: Contexto, 2009. p. 27-64

BRAUDEL, Fernand, Escritos sobre a História. São Paulo: Perspectiva, 2009.

CERTEAU, Michel de. A escrita da história. 2. ed. Rio de Janèiro: Forense, 2002. História e psicanálise: entre ciência e ficção. Belo Horizonte: Autêntica, 2016.

DOSSE, François: A história em migalhas. Dos Annales à Nova História. Campinas: Unicamp, 1992.

FRACOSO, João; FLORENTINO, Manolo. História Econômica. In: CARDOSO, Ciro F.; VAINFAS, Ronaldo (Orgs.). Domínios da história; ensaios de teoria e metodologia. Rio de Janeiro: Campus, 1997. p. 53-75. Disponivel em: <http://groups.google.com/group/digitalsourc>. Acesso em: 29 jun. 2016.

FUETER, Eduard. (1911). Historia de la Historiografía Moderna. Buenos Aires: Editorial Nova, 1953. $3 \mathrm{~V}$.

COMES, Sandro A. R. Descentralização e pragmatismo: condições sociais de produção das memórias históricas de Antonio Vieira dos Santos (Morretes e Paranaguá, décadas de 1840-1850). 2012. Dissertação (Mestrado em História) - Universidade Federal do Paraná, Curitiba. 2012.

CONTIJO, Rebeca. José Honório Rodrigues e a invenção de uma moderna tradição. In: NEVES, Lucia M. B. P. das. et al. (Orgs.). Estudos de historiografia brasileira. Rio de Janeiro: FCV, 2011. p. $277-290$. 
CUIMARÃES, Lucia M. P. Sobre a história da historiografia brasileira como campo de estudos e reflexões. In: NEVES, Lucia M. B. P. das. et al. (Orgs.). Estudos de historiografia brasileirra. Rio de Janeiro: FCV, 2011. p. 19-35.

GUIMARÃES, Manoel L. S. Historiografia e cultura histórica: notas para um debate. Ágora, Santa Cruz do Sul, v. 11, n. 1, p. 31-47, jan:/jun. 2005.

HARTOG, François. Evidência da história: o que os historiadores veem. Belo Horizonte: Autêntica, 2011.

HENRY, Louis; BALHANA, Altiva P. La populacion du Paraná depuis le XVIlle siècle. Population, Paris, n. 30, p. 157-186, 1975.

IGLÉSIAS, Francisco. Historiadores do Brasil: capítulos de historiografia brasileira. Rio de Janeiro: Nova Fronteira; Belo Horizonte: UFMG; IPEA, 2000.

LEJEUNE, Philippe. O pacto autobiográfico: de Rousseau à Internet. Belo Horizonte: UFMG, 2008.

LINHARES, Temístocles. Paraná vivo: sua vida, sua gente, sua cultura. Rio de Janeiro: José Olympio, 1953.

MACHADO, Brasil P. Esboço de uma sinopse da história regional do Paraná. In: SEPARATA do Boletim do Instituto Histórico, Ceográfico e Etnográfico do Paraná. Curitiba: IHCE-PR, jul. 1957.

MACHADO, Daiane V. Por uma "ciência histórica": o percurso intelectual de Cecília Westphalen, 1950-1998. 2016. Tese (Doutorado em História) - Universidade Estadual Paulista, Assis. 2016.

Texto historiográfico como construção autobiográfica: Cecília Westphalen e a historiografia paranaense. In: SIMPÓSIO NACIONALL DE HISTÓRIA - ANPUH, 28, 2015, Florianópolis. Anais... Florianópolis: Anpuh, 2015. p. 1-14.

MARCHETTE, Tatiana D. A trajetória de Brasil Pinheiro Machado e a construção da historiografia do Paraná no território acadêmico (1928-1953): do poema ao modelo historiográfico. 2013. Tese (Doutorado em História) - Universidade Federal do Paraná, Curitiba. 2013.

MARTINS, Wilson. Um Brasil diferente: ensaio sobre fenômenos de aculturação no Paraná. São Paulo: Anhembi, 1955.

MASTROGRECORI, Massimo. Historiografia e tradição das lembranças. In: MALERBA, Jurandir (Org). A história escrita: teoria e história da historiografia. São Paulo: Contexto, 2009. p. 65-93.

MORAES, Pedro R. B.; SOUZA, Marcilene G. Invisibilidade, preconceito e violência racial em Curitiba. Revista Sociologia e Política, Curitiba, n. 13, p. 7-76, nov. 1999. 
MOTTA, José F. Agonia ou robustez? Reflexões acerca da historiografia econômica brasileira. Revista de Economia da PUC-SP, São Paulo, n. 1, p. 117-138, jan./jun. 2009.

NOIRIEL, Gérard. Fernand Braudel, comment on récrit l'histoire. In: Penser.avec, penser contre. Itinéraire d'un historien. Paris: Belin, 2014

(1996). Surla "crise" de l'histoire. Paris: Callimard, 2005.

OGANAUSKAS, Flávia R. M. Memória e identidade regional paranaense: o contraponto historiográfico de um Paraná suigeneris. In: TRINDADE, Alexandro D.; COSTA, Hilton; ROIZ, Diogo da S. (Orgs.). À margem do(s) cânone (s): pensamento social e interpretações do Brasil: Curitiba: UFPR, 2013. p. 147-172.

RODRICUES, Henrique E.; NICOLAZZI, Fernando. Entrevista com François Hartog: história, historiografia e tempo presente. História da historiografia, Ouro Preto, n. 10, p. 356-357, dez. 2012.

SILVA, Deiver B. da; ALVES, Hober L; ASSUNÇÃO, Marcelo F. M. Entrevista com o Prof. Dr. Valdei Lopes Araujo (UFOP). Revista de Teoria da História, Goiás, ano 6, n. 11, p. 309-323, mai: 2014

TURIN, Rodrigo. História da historiografia e memória disciplinar: reflexões sobre um gênero. História da historiografia, Ouro Preto, n.13, p. 78-95, 2013.

WESTPHALEN, Cecília M. Pequena História do Paraná. São Paulo: Melhoramentos, 1953.

Carlos-Quinto, 1500/7558: seu império universal. 1955. Tese (Doutorado em História) Universidade Federal do Paraná, Curitiba. 1955.

Comentário. In: SEMINÁRIO DE ESTUDOS BRASILEIROS [Encontro Internacional de Estudos Brasileiros], 1., 1971, São Paulo. Anais... São Paulo: Universidade de São Paulo/Instituto de Estudos Brasileiros, 1972. p. 36-43.

Oitenta anos de Fernand Braudel. Boletim do Conselho Federal da Cultura, Rio de Janeiro, v. 12, n. 46, p. 133-135; jan./mar. 1982.

Fernand Braudel: teoria e ideologia. In: SOCIEDADE BRASILEIRA DE PESQUISA HISTÓRIA (SBPH), 2, 1982, São Paulo. Anais... São Paulo: SBPH, 1983a, p. 161-174.

Historiografia paranaense. Revista do Instituto Histórico e Ceográfico Brasileiro, Brasília/ Rio de Janeiro, n. 343, p. 105-126, abr./jun. 1984.

Momentos da historiografia paranaense. In: SOCIEDADE BRASILEIRA. DE PESQUISA HISTÓRIA (SBPH), 4., 1984, Rio de Janeiro. Anais... São Paulo: SBPH, 1985a, p. 59-61.

$39,7985 b$

Fernand Braudel: teoria e ideologia. Ciências Humanas, Rio de Janeiro, v. 8, n. 26, p. 28- 
Apresentação. Mesa-redonda: A situação da História econômica no Brasil nas últimas três décadas. In: SOCIEDADE BRASILEIRA DE PESQUISA HISTÓRIA (SBPH), 5., 1985, São Paulo. Anais... São Paulo: SBPH, 1986, p. 71-72.

Porto de Paranaguá, um sedutor. Curitiba: Secretaria de Estado da Cultura, 1998.

A Palaura do Sul. Cem anos de Gilberto Freyre. Curitiba: CD, 2000. 